\title{
Pengembangan Aplikasi Retail Dengan Sistem Konfigurasi
}

\author{
Liliana $^{1^{*}}$, Dhiani Tresna Absari ${ }^{2}$, Felicia Brilliant Benaly ${ }^{3}$ \\ 1,2,3 Program Studi Teknik Informatika, Fakultas Teknik, Universitas Surabaya \\ Email: ${ }^{1 * 1}$ lili@ staff.ubaya.ac.id, ${ }^{2}$ dhiani@ @staff.ubaya.ac.id, ${ }^{3}$ feliciabrilliantb@gmail.com
}

(Naskah masuk: 15 Okt 2020, direvisi: 4 Nov 2020, diterima: 5 Nov 2020)

\begin{abstract}
Abstrak
Teknologi secara konstan mengalami perkembangan. Dari sistem berbasis kertas, berubah menjadi sistem berbasis komputer, dengan berbagai perubahan yang menjanjikan kemudahan untuk penggunanya. Salah satu sektor yang mengalami banyak perubahan adalah sistem penjualan retail. Saat ini, kebanyakan toko yang membutuhkan sistem terkomputerisasi, memesan ke developer sistem untuk dibuatkan sistem sesuai kebutuhannya. Namun pada dasarnya, sistem penjualan retail kebanyakan memiliki kemiripan cukup tinggi. Proses bisnis yang terjadi pada sistem penjualan retail, antara lain penjualan retail, penjualan dengan hutang, penentuan harga retail dan grosir, pengiriman, dan proses bisnis lainnya. Apabila kebutuhan sistem yang memiliki kemiripan ini terus dibuat berulang kali setiap kali pengembang menerima projek sistem penjualan retail, maka hal ini dapat membuang waktu dan tenaga dari sisi developer. Oleh karena itu, dibutuhkan sistem yang menyediakan berbagai fitur penjualan retail secara umum dan dapat dikonfigurasi, sehingga user dapat mengatur sendiri kebutuhan sistemnya. Dengan demikian, sumber daya yang dibutuhkan untuk membangun sistem menjadi lebih kecil. Sistem konfigurasi dibangun berbasis web, dan telah diujicobakan pada dua toko retail yang memiliki kemiripan proses bisnis, dengan detail spesifikasi kebutuhan yang berbeda. Hasil uji coba menunjukkan bahwa dengan adanya sistem konfigurasi ini, pemilik sistem dapat mengatur kebutuhan sistemnya dengan lebih mudah dan menggunakan kembali sistem dalam waktu yang singkat, tanpa harus melibatkan developer.
\end{abstract}

Kata Kunci: sistem penjualan retail, konfigurasi, sistem informasi, sistem berbasis web.

\section{Retail Application Development with Configuration System}

\begin{abstract}
Technology is constantly undergoing development. From paper-based system, to computer-based system, with various changes that promise convenience for its users. One of the sectors that has undergone many changes is the retail sales system. Currently, most shops that require computerized system, order system developers to produce digitized systems in accordance to their necessities. Basically, most retail sales systems have systems that are quite similar. Business processes that occur include retail sales, debt sales, retail and wholesale pricing, shipping and other business processes. If the need for such system with similar arrangement continues to be made from scratch, then it will take a lot of time and effort. Therefore, a system that provides various retail general features and can be configured with ease is required, so that the users can configure their own system requirements based on their own settings. Thus, the resources needed to build the system becomes more efficient. The configuration system is built based on web, and has been tested in two retail stores which have similar business process, with different detail requirement. The test results show that with this configuration system, users can manage their own system requirements more easily in a short period of time.
\end{abstract}

Keywords: retail application, configurable, information system, web based. 


\section{PENDAHULUAN}

Sektor usaha retail memegang peranan yang cukup penting dalam roda perekonomian sebuah negara [1]. Di Indonesia sendiri, pada tahun 2017, nilai penjualan retail mencapai USD350 miliyar, atau sekitar 4,6 kuadriliun [2]. Retail atau ritel adalah aktivitas perniagaan yang melibatkan penjualan barang atau jasa secara langsung kepada konsumen akhir, yang pada umumnya digunakan untuk keperluan pribadi [3].

Perkembangan perekonomian, menuntut peningkatan kecepatan dan kualitas dari proses bisnis [4]. Pemanfaatan teknologi, tidak lagi didominasi oleh pemain berskala besar [5]. Bahkan dalam perkembangannya, teknologi menentukan daya saing dari berbagai level organisasi dalam pasar [6]. Sistem berbasis komputer memiliki peranan yang penting dalam proses bisnis suatu organisasi, khususnya pada sektor usaha retail [7]. Manfaat yang dijanjikan oleh sistem retail berbasis komputer antara lain kemudahan membuat nota, pencatatan hutang, stok, pengelolaan data konsumen, dan manfaat lainnya.

Pemain bisnis dalam sektor usaha retail kecil dan menengah, pada umumnya akan mencari developer untuk membantu mereka mengembangkan sistem informasi berbasis komputer, yang sesuai dengan kebutuhan mereka. Developer akan melakukan proses pengembangan aplikasi dari awal, seperti tahapan analisis, desain dan implementasi secara berulang. Proses ini, selain membutuhkan waktu dan tenaga yang tidak sedikit, juga mengurangi usia produk saat diimplementasikan [8], [9]. Tidak jarang, proses ini berujung dengan kelelahan di kedua belah pihak karena komunikasi yang kurang baik, faktor psikologis dan banyak faktor lainnya; dan mengakibatkan gagalnya proses implementasi sistem.

Pada sistem yang berjalan, ada kalanya terjadi perubahan kebutuhan sistem. Pada sistem konvensional, pemilik sistem harus mencari kembali developer awal yang membangun sistem, untuk melakukan perombakan sistem. Misalnya pada awal usaha, karena ukuran toko yang masih kecil, maka toko tidak menyediakan konsinyasi ataupun harga grosir. Seiring dengan waktu, karena ukuran usaha yang semakin meluas, pemilik usaha memutuskan untuk menyediakan harga grosir untuk konsumen yang berbelanja dalam jumlah banyak. Perombakan sistem seperti ini, yang dilakukan setelah program berjalan, membutuhkan sumber daya yang relatif besar dan beresiko akan menimbulkan error yang tidak diharapkan pada sistem [10], [11]. Adakalanya, pemilik sistem lebih memilih untuk membuat ulang sistem terkomputerisasinya, agar dapat menyesuaikan dengan proses bisnis yang baru.

Salah satu solusi yang dapat dilakukan untuk mengatasi masalah di atas adalah dengan membangun suatu sistem yang dapat dikonfigurasi [8]. Dalam penelitian ini, sistem dikembangkan dengan mempertimbangkan berbagai faktor yang dibutuhkan dalam suatu sistem penjualan retail, yang didapatkan dari proses analisis terhadap beberapa objek studi kasus yang berupa toko dengan penjualan retail yang memiliki kondisi berbeda [12].

Dengan adanya sistem yang dapat dikonfigurasi, maka toko dengan berbagai proses bisnis yang berbeda, dapat menggunakannya. Diharapkan dengan demikian, dapat mengurangi sumber daya yang dikeluarkan, serta dapat meningkatkan daya saing toko dalam penjualan retailnya.

\section{PRODUK KONFIGURASI}

Produk konfigurasi adalah produk yang diproduksi secara masal, dan dapat beradaptasi dengan kebutuhan, dimana produk ini memiliki berbagai karakteristik umum yang dibutuhkan penggunanya, dan dalam penggunaannya, dapat disesuaikan dengan apa yang dibutuhkan [8], [10]. Beberapa karakteristik umum yang wajib ada dalam produk konfigurasi adalah:

- Produk konfigurasi didesain dapat memenuhi kebutuhan pengguna dengan berbagai karakteristik

- Produk yang diluncurkan memiliki karakteristik khusus yang sudah diatur agar sesuai dengan kebutuhan penggunanya, dimana developer tidak perlu menambahkan fitur baru pada sistem.

Dalam pengembangan sebuah aplikasi yang dapat dikonfigurasi, developer tidak mengkhususkan diri pada satu kondisi perusahaan. Studi kasus yang dipelajari wajib mencakup berbagai kondisi. Usaha ini ditujukan agar produk ini dapat digunakan oleh pengguna lainnya, dengan pengaturan sistem yang berbeda.

\section{HASIL DAN PEMBAHASAN}

\section{A. Metodologi Penelitian}

Proses pembuatan sistem dilakukan menggunakan Software Development Life Cycle (SDLC) konsep waterfall. Model ini berjalan secara sekuensial, dimana pengembangan perangkat lunak dilakukan melalui fase-fase yang berurutan [13]. Tahapan analisis pada penelitian ini dilakukan pada beberapa toko retail, yaitu beberapa toko sembako, toko alat tulis, dan toko peralatan komputer. Selain itu, juga dilakukan benchmarking terhadap sistem serupa, yaitu prestashop [14], redtick [15], dan pesansembako.com [16]. Tahapan analisis memegang peranan yang paling penting dalam penelitian ini, karena pada tahap inilah, faktor-faktor yang akan dikonfigurasi ditentukan.

Selanjutnya dilakukan tahap desain, dengan membuat Entity Relationship Diagram (ER-Diagram) [17], Business Process Model And Notation (BPMN) [18], dan desain antar muka yang sesuai dengan hasil analisis. Hasil desain akan dikembangkan menjadi aplikasi berbasis web, menggunakan bahasa pemrograman PHP, dengan framework Laravel dan database MySQL, serta memanfaatkan Google Maps API [19]. Pada tahap uji coba, dilakukan konfigurasi terhadap dua toko yang berbeda, dengan skenario yang sesuai dengan kebutuhan sistem toko tersebut.

\section{B. Hasil Penelitian}

Analisis sistem saat ini dilakukan dengan pengamatan secara langsung pada beberapa toko retail, wawancara pada pemiliki toko, serta kuisioner pada konsumen toko retail. Creative adaptation diambil dari proses benchmarking ke 
beberapa situs retail. Hasil analisis yang didapatkan adalah berupa faktor-faktor yang diharapkan dapat dikonfigurasi, seperti pada Tabel 1. Hasil analisis sistem digunakan sebagai dasar dalam tahapan desain data, proses dan antar muka, dan selanjutnya diimplementasikan menjadi aplikasi yang sesungguhnya.

Tabel 1. Konfigurasi

\begin{tabular}{ll}
\multicolumn{1}{c}{ Faktor } & \multicolumn{1}{c}{ Nilai Konfigurasi } \\
\hline Pengeluaran stok & $\begin{array}{l}\text { FIFO dengan mencatat } \\
\text { tanggal kadaluarsa / bebas }\end{array}$ \\
\hline Jenis pembayaran & $\begin{array}{l}\text { Tunai, hutang, cash on } \\
\text { delivery, transfer }\end{array}$ \\
\hline Jika transfer & $\begin{array}{l}\text { Ada pengaturan data } \\
\text { rekening }\end{array}$ \\
\hline Retur penjualan & On / Off \\
\hline Konsinyasi (titip jual) & On / Off \\
\hline Pengiriman & On / Off \\
\hline Jika ada pengiriman & $\begin{array}{l}\text { Ada pengaturan jarak } \\
\text { maksimal pemesanan dan } \\
\text { ongkos kirim }\end{array}$ \\
\hline Harga grosir & On / Off \\
\hline Jika harga grosir & $\begin{array}{l}\text { Ada penentuan jumlah } \\
\text { minimal grosir }\end{array}$ \\
\hline Pembatalan pesanan & On / Off \\
\hline Jika diijinkan membatalkan & $\begin{array}{l}\text { Ada batasan maksimal } \\
\text { waktu yang diijinkan untuk } \\
\text { membatalkan }\end{array}$ \\
\hline Retur penjualan & On / Off \\
\hline Global / masing-masing \\
produk
\end{tabular}

Data didesain untuk semua kondisi yang dapat dikonfigurasi. Oleh karena itu, desain database menjadi cukup kompleks karena apapun kondisi yang dipilih oleh user, sistem telah menyediakan tempat penyimpanannya. Desain data dapat dilihat pada Gambar 4.

Desain proses utama dapat dilihat pada Gambar 1. Sebelum sistem digunakan oleh masing-masing toko, setiap faktor yang telah ditentukan, dikonfigurasikan ke sistem, dimana implementasi user interface dapat dilihat pada Gambar 2. Semua proses konfigurasi dapat diubah selama perjalanan sistem, kecuali pada metode pembayaran hutang dan metode pengeluaran stok.

Setelah proses konfigurasi selesai, maka superadmin dapat menggunakan sistem, seperti pada desain user interface di Gambar 3. Pada halaman dashboard ini, pengguna akan mendapatkan pengingat untuk beberapa hal penting, seperti jumlah pesanan yang belum diproses, jumlah pesanan yang harus dikirim, jumlah pesanan yang perlu dibatalkan, serta barang yang mencapai stok minimal atau perlu dilakukan restock. Desain proses penjualan online dapat dilihat pada Gambar 5, dan desain proses konsinyasi dapat dilihat pada Gambar 6.

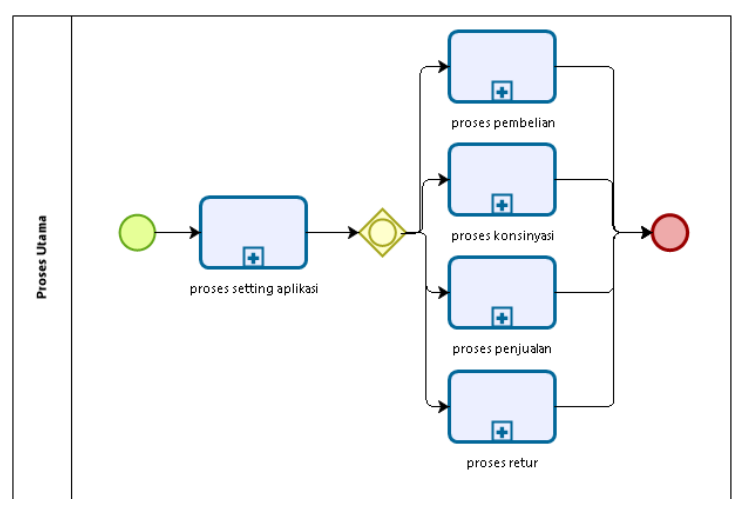

Gambar 1. Desain Proses Utama

Untuk dua skenario yang telah ditentukan, masing-masing pengguna dari toko diminta untuk menggunakan sistem untuk menjalankan proses bisnisnya. Uji coba meliputi pemesanan online dan offline oleh konsumen, transaksi konsinyasi, transaksi tunai dan hutang, pembatasan hutang konsumen, pemotongan stok. Semua proses bisnis menggunakan alur standar yang umum digunakan di toko retail, sesuai dengan pengaturan awal yang telah ditentukan.

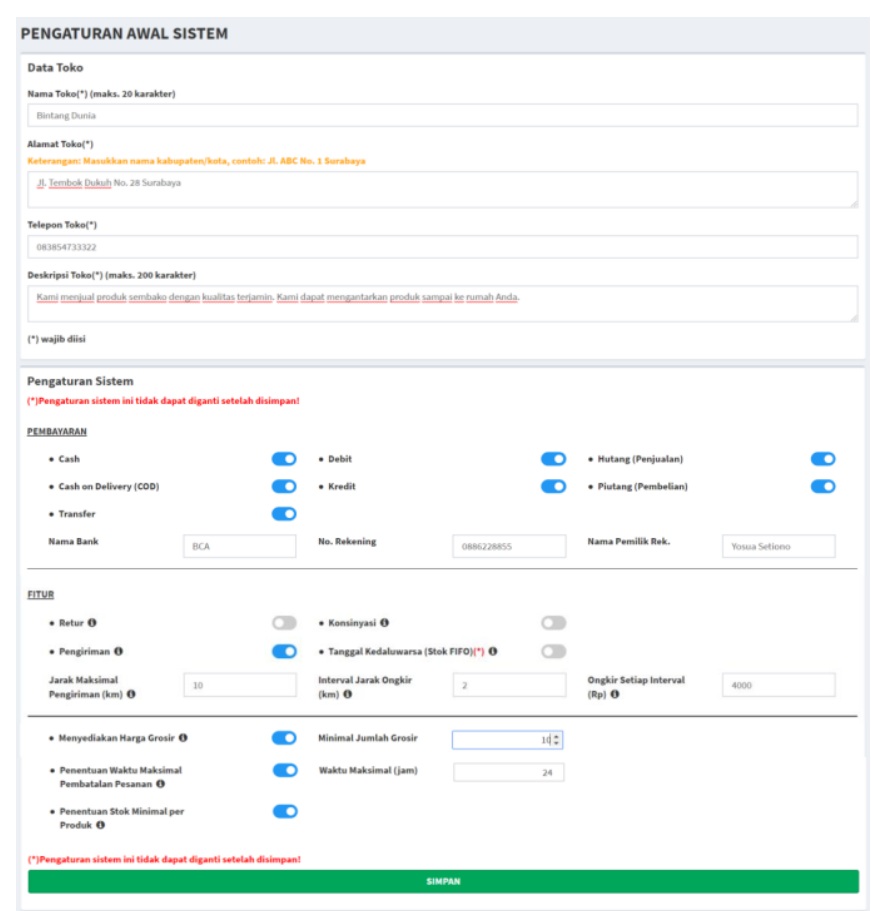

Gambar 2. Halaman Konfigurasi

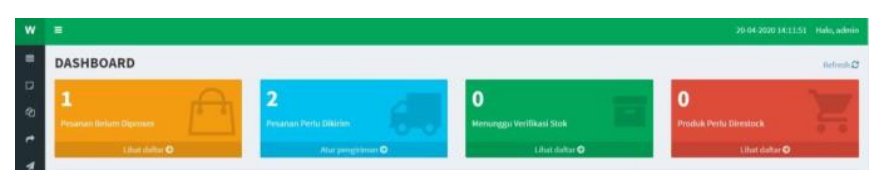

Gambar 3. Dashboard Superadmin 


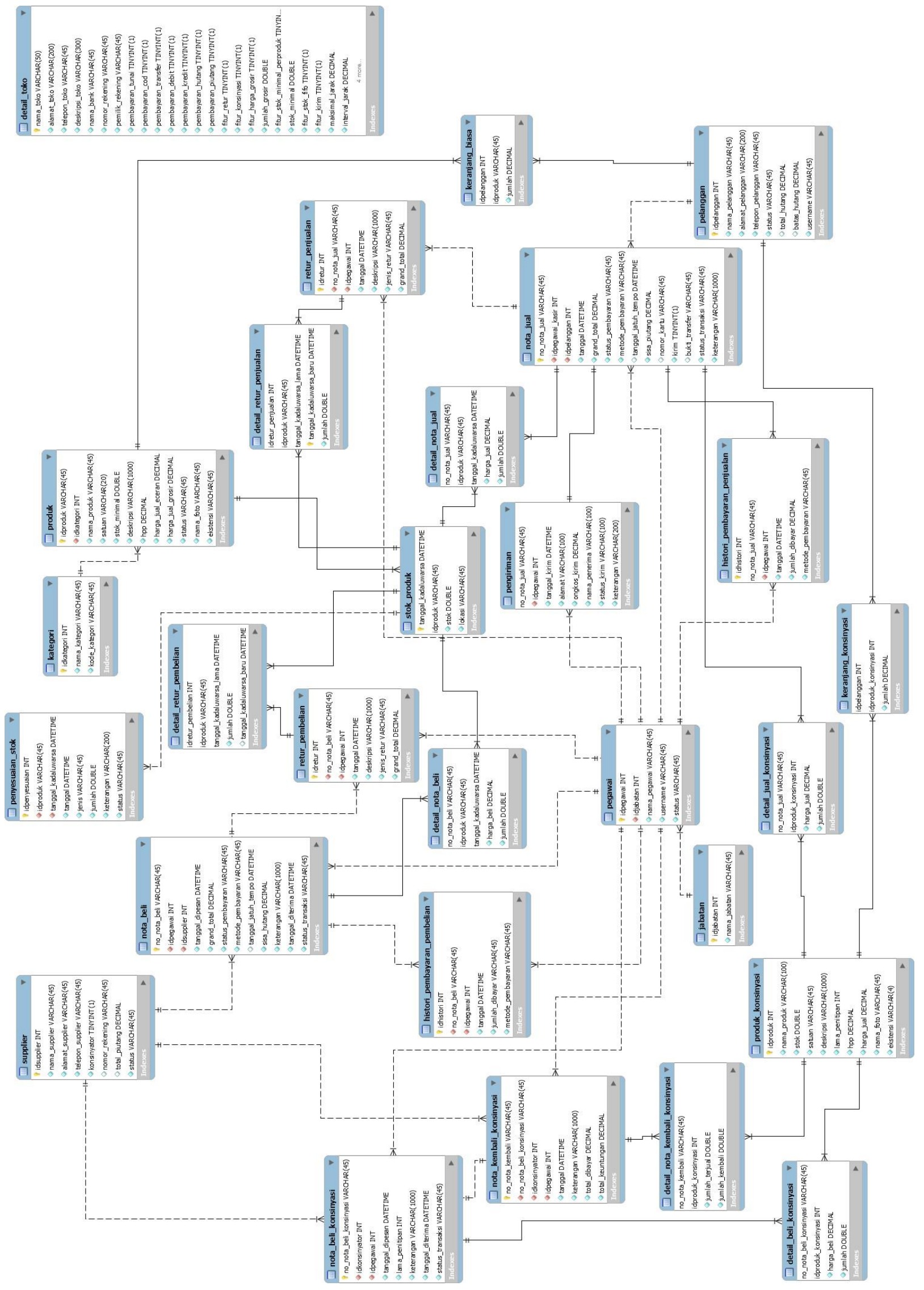

Gambar 4. Desain Data 


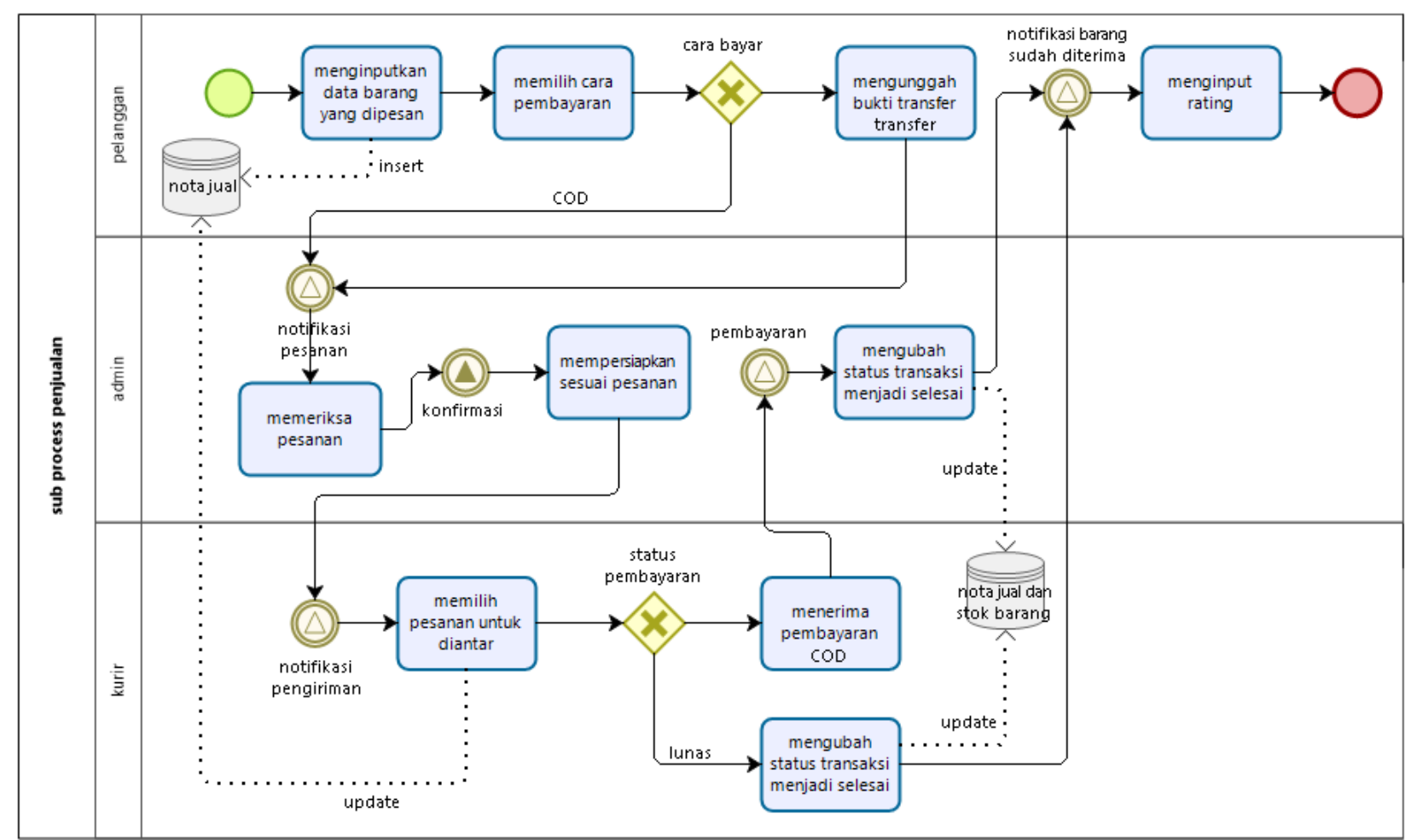

Gambar 5. Desain Proses Penjualan Online

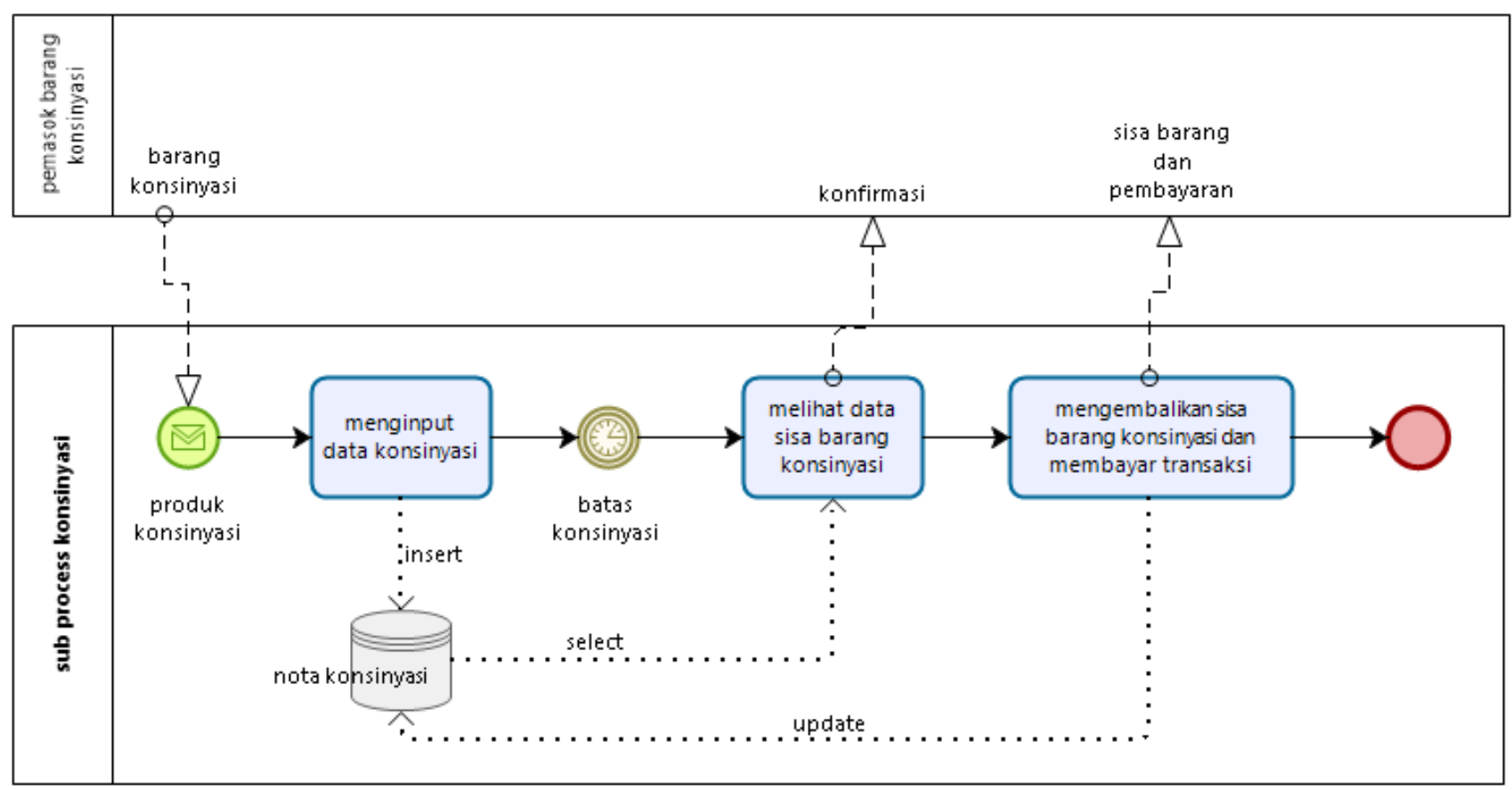

Gambar 6. Desain Proses Penjualan Konsinyasi

Pada fitur pengiriman, sistem dapat mengenali jarak dari toko ke tujuan. Setelah pesanan dikonfirmasi oleh toko, maka kurir toko akan menerima daftar pesanan yang harus dikirimkan, seperti pada Gambar 7. Pada fitur ini, sistem dapat memberikan rekomendasi rute terbaik yang dapat dilalui oleh kurir. Selain itu, kurir juga mendapatkan informasi mengenai cara pembayaran, apakah transaksi tersebut sudah lunas atau COD.

Pada tahap uji coba, dilakukan terhadap dua toko retail yang memiliki kebutuhan sistem berbeda. Skenario yang digunakan dalam tahap uji coba ini dapat dilihat pada Tabel 2. 


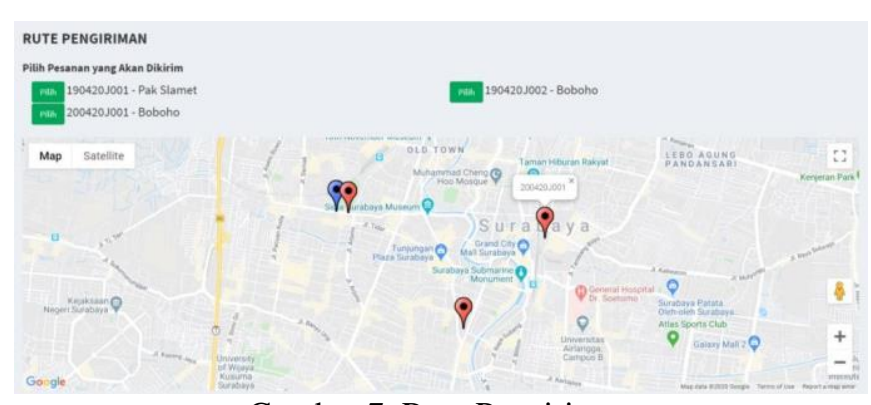

Gambar 7. Rute Pengiriman

Dari hasil uji coba yang dilakukan dengan menerapkan dua skenario sistem, dan kemudian dilakukan wawancara terhadap pemilik dan pegawai toko, serta konsumen toko, didapatkan pernyataan bahwa sistem relatif mudah digunakan dan telah memenuhi kebutuhan sistem pada masing-masing toko. Tahap berikutnya, uji coba dilakukan dengan mengubah pengaturan sistem, misal dengan mematikan salah satu metode pembayaran dan mengnonaktifkan harga grosir. Setelah perubahan, sistem masih bisa digunakan dengan baik dan lancar.

Adanya fitur konfigurasi dianggap membantu toko untuk memiliki sistem informasi berbasis komputer dalam waktu singkat, dengan biaya optimal. Hal ini dimungkinkan terjadi karena dari sisi developer, dengan satu kali membuat aplikasi, dapat digunakan untuk beberapa kondisi toko retail. Dari sisi pemilik sistem, dengan adanya kemampuan sistem untuk mengubah proses bisnis dalam batasan tertentu, sangat menghemat waktu dan biaya modifikasi atau pembuatan sistem baru.

\begin{tabular}{clll}
\multicolumn{4}{c}{ Tabel 2. Skenario Uji Coba } \\
\hline No & \multicolumn{1}{c}{ Fitur } & \multicolumn{1}{c}{ Toko A } & \multicolumn{1}{c}{ Toko B } \\
\hline 1 & $\begin{array}{l}\text { Metode } \\
\text { pembayaran }\end{array}$ & $\begin{array}{l}\text { Tunai, transfer, } \\
\text { COD, kartu debit, } \\
\text { kartu debit, } \\
\text { hutang, piutang }\end{array}$ & $\begin{array}{l}\text { Tunai, } \\
\text { transfer, } \\
\text { hutang, } \\
\text { piutang }\end{array}$ \\
\hline 2 & Retur & Diaktifkan & Diaktifkan \\
\hline 3 & Konsinyasi & Diaktifkan & Dinonaktifkan \\
\hline 4 & Pengiriman & Diaktifkan & Diaktifkan \\
\hline 5 & $\begin{array}{l}\text { Penyimpanan } \\
\text { FIFO }\end{array}$ & Diaktifkan & Dinonaktifkan \\
\hline 6 & $\begin{array}{l}\text { Penentuan } \\
\text { batas hutang } \\
\text { maksimal }\end{array}$ & Diaktifkan & Dinonaktifkan \\
\hline 7 & Harga grosir & Diaktifkan & Diaktifkan \\
\hline 8 & $\begin{array}{l}\text { Penentuan } \\
\text { waktu } \\
\text { maksimal } \\
\text { pembatalan } \\
\text { pesanan }\end{array}$ & Diaktifkan & Dinonaktifkan \\
\hline 9 & $\begin{array}{l}\text { Penentuan } \\
\text { stok minimal }\end{array}$ & Per produk & \\
\hline
\end{tabular}

\section{KESIMPULAN}

Dari penelitian ini, dapat disimpulkan bahwa produk konfigurasi pada sistem tertentu memiliki dampak yang signifikan. Integrasi antar user, yaitu konsumen, admin dan kurir di lapangan, menggunakan satu aplikasi, mempermudah koordinasi dan mengurangi kesalahan yang terjadi akibat human error.

Selain itu dari sisi developer, waktu yang dibutuhkan untuk mengembangkan sistem relatif panjang, terutama di bagian analisis. Namun apabila dibandingkan dengan manfaat yang didapatkan, yaitu satu sistem dapat dijual ke beberapa toko dengan proses bisnis berbeda, maka proses ini dianggap cukup menguntungkan. Terlebih lagi mengingat sistem retail di Indonesia masih cukup umum dan memiliki kemiripan proses bisnis yang tinggi.

Dari sisi pemilik toko, waktu implementasi yang singkat dan biaya pengadaan sistem terkomputerisasi yang relatif lebih rendah dibandingkan pembuatan sistem dari awal, dapat meningkatkan daya saing pada bisnisnya. Dampak perubahan kebutuhan perubahan proses bisnis setelah sistem digunakan, juga dapat diatasi dengan baik pada produk konfigurasi.

\section{LIMITASI PENELITIAN}

Dalam penelitian ini, objek yang digunakan sebagai studi kasus adalah dua toko yang menjual sembako dan peralatan komputer. Kedua objek ini dianggap belum dapat mewakili seluruh kondisi dari sektor retail yang ada.

Selain itu, karena kondisi pandemi, peneliti tidak dapat melakukan uji coba lebih mendalam terhadap konsumen sebagai salah satu pengguna aplikasi. Hal ini menyebabkan penilaian dari sisi konsumen belum didapatkan.

Untuk pengembangan fitur yang disediakan, fitur peta yang digunakan dalam sistem masih minimal, dan dapat dieksplorasi sesuai fitur yang telah disediakan pada Google Map. Selain itu, pada sistem ini belum terdapat fitur diskon, yang memiliki tingkat kerumitan tersendiri.

Karena keterbatasan sumber daya dalam penelitian ini, kerjasama dengan pihak ketiga, misal untuk pembayaran menggunakan payment gateway, tidak dilakukan.

\section{REFERENSI}

[1] Becker, J. \& Schütte, R. (2004). Retail Information Systems. pp. 1-5.

[2] Kearney, A.T. (2017). Berapa Nilai Penjualan Ritel Indonesia? Databoks [Online]. Diakses dari: https://databoks.katadata.co.id/datapublish/2017/06/06/ berapa-nilai-penjualan-ritel-indonesia.

[3] Ramadhani, N. (2020). Ritel: Pengertian, Fungsi, dan Jenisnya [Online]. Diakses dari: https://www.akseleran.co.id/blog/ritel-adalah/.

[4] Zhang, S.W. \& Li, Z.H. (2011). A Configurable Platform of Application System and Its End-UserOriented Configuration-Developing Pattern. Advanced Materials Research, Vol. 219-220, pp. 1415-1418. 
[5] Barantum. (2019). 6 Trend Bisnis yang akan Mempengaruhi Bisnis Retail di Indonesia [Online]. Diakses dari: https://www.barantum.com/blog/trenbisnis-ritel/.

[6] Perantara. (2018). Situs Informasi Bisnis dan Peluang Usaha Indonesia [Online]. Diakses dari: https://perantara.net/sistem-informasi-bisnis-retailberadaptasi/.

[7] Hakim, F.N., Febriani, Y. \& Solechan, A. (2019). Pengembangan Sistem Informasi Penjualan, Pembelian Dan Persediaan Berbasis Web. Jurnal SITECH: Sistem Informasi dan Teknologi, Vol. 1(2), pp. 155-160.

[8] Tiihonen, J. \& Soininen, T. (1997). Product Configurators - Information System Support for Configurable Products. Laboratory of Information Processing Science, Helsinki University of Technology.

[9] Salvador, F. \& Forza, C. (2004). Configuring Products to Address The Customization-responsiveness Squeeze: A Survey of Management Issues and Opportunities. International Journal of Production Economics, Vol. 91(3), pp. 273-291.

[10] Heiskala, M., Paloheimo, K. \& Tiihonen, J. (2005). Mass Customisation of Services: Benefits and Challenges of Configurable Services. Frontiers of $E$ Business Research, pp. 206-221.

[11] ITTelkom. (2019). Software Maintenance, Bagian Penting yang Sering Diabaikan. [Online]. Diakses dari: http://se.ittelkom-pwt.ac.id/software-maintenancebagian-penting-yang-sering-diabaikan/.

[12] Forza, C. \& Salvador, F. (2002). Managing for Variety in The Order Acquisition and Fulfilment Process: The Contribution of Product Configuration Systems. International Journal of Production Economics, Vol. 76(1), pp. 87-98.

[13] Balaji, S. (2012). Waterfall Vs V-Model Vs Agile: A Comparative Study on SDLC. International Journal of Information Technolology Business Management, Vol. 2(1), pp. 26-30.

[14] PrestaShop. (2020). Create and Develop Your Business with PrestaShop [Online]. Diakses dari: https://www.prestashop.com/en.

[15] Redtick (2018). Redtick [Online]. Diakses dari: https://shop.redtick.com/.

[16] PT Khalifa Sembako Agromitra. (2018). PesanSembako.com [Online]. Diakses dari: https://www.pesansembako.com/.

[17] Dybka, P. (2020). Crow's Foot Notation [Online]. Diakses dari: https://www.vertabelo.com/blog/crow-sfoot-notation/.

[18] BPMN. (2020). BPMN [Online]. Diakses dari: http://www.bpmn.org/.

[19] Google Cloud. (2020). Google Cloud [Online]. Diakses dari: https://cloud.google.com/maps-platform. 